Holtkamp, C.C.M., Kerkstra, A., Ribbe, M.W., Campen, C. van, Ooms, M.E.

The relation between quality of co-ordination of nursing care and quality of life in

Dutch nursing homes.

Journal of Advanced Nursing: 32, 2000, nr. 6, p. 1364-1373

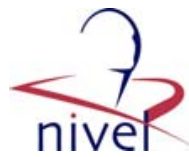

\begin{tabular}{|l|l|}
\hline Postprint Version & 1.0 \\
\hline Journal website & $\underline{\text { http://www.blackwell-synergy.com/loi/jan }}$ \\
\hline Pubmed link & $\begin{array}{l}\text { http://www.ncbi.nlm.nih.gov/entrez/query.fcgi?cmd=Retrieve\&db=pubmed\&dop } \\
\text { t=Abstract\&list_uids=11136404\&query_hl=23\&itool=pubmed_docsum }\end{array}$ \\
\hline DOI & $10.1046 / \mathrm{j} .1365-2648.2000 .01626 . x$
\end{tabular}

\title{
The relation between quality of co-ordination of nursing care and quality of life in Dutch nursing homes
}

\author{
HOLTKAMP C.C.M., KERKSTRA A., RIBBE M.W., VAN CAMPEN C. \& OOMS M.E.
}

Chantal C.M. Holtkamp MSc RN Research Fellow, Netherlands Institute of Primary Health Care, Utrecht

Ada Kerkstra PhD Head of the Department of Nursing and Caring Research, Netherlands Institute of Primary Health Care, Utrecht

Miel W. Ribbe MD PhD Professor, Department of General Practice, Nursing Home Medicine and Social Medicine, Vrije Universiteit, Amsterdam

Crétien van Campen PhD Research Fellow, Department of Nursing and Caring Research, Netherlands Institute of Primary Health Care, Utrecht

and Marcel E. Ooms MD PhD Institute for Research in Extramural Medicine (EMGO), Vrije Universiteit, Amsterdam, The Netherlands

Correspondence: Chantal Holtkamp, Netherlands Institute of Primary Health Care (NIVEL), PO Box 1568, 3500 BN Utrecht, The Netherlands. E-mail: c.holtkamp@nivel.nl

Quality of life of nursing home residents is a critical consideration in international health care policies and health care decisions. Yet, there is little relevant research to support decisions about client-tailored and effective nursing care for this population. Because of the permanency of their stay, the care received affects the quality of daily life. This study investigated the quality of co-ordination of care and the way it is related to gaps between needs and care supply, the quality of life and health status of residents living in Dutch nursing homes. To assess the perceived quality of life and experienced discrepancies between needs and care supply, 337 residents of 10 different nursing homes were interviewed. The quality of co-ordination of nursing care was assessed by judgements of the residents and nurses and by analysing the care documents. The results showed a relation between the co-ordination of care and care discrepancies; the higher the quality of co-ordination of care, the fewer the gaps between residents' needs and the care they received. The psycho-social aspects in particular showed a gap between the needs and care supply. As regards the relation between co-ordination of care and quality of life, the strongest positive relations were found between taking case histories, patient allocation and dimensions of quality of life. No direct relations were found between the coordination of care and care discrepancies on the one hand and the health status of the residents on the other.

In conclusion, this study showed that the quality of co-ordination of care can affect the perceived quality of life of nursing home residents. To meet the residents' needs it is important to assess their physical and psycho-social needs accurately. More research focusing on this assessment is needed in order to improve the quality of life of nursing home residents. 
Holtkamp, C.C.M., Kerkstra, A., Ribbe, M.W., Campen, C. van, Ooms, M.E.

The relation between quality of co-ordination of nursing care and quality of life in

Dutch nursing homes.

Journal of Advanced Nursing: 32, 2000, nr. 6, p. 1364-1373

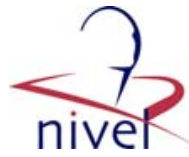

\section{INTRODUCTION}

Quality of life and client-tailored care have become important targets of health care policies in Western, industrialized countries. This applies to residents of nursing homes especially because of the permanency of their situation. Accordingly the care received affects the quality of daily life (Grant et al. 1996). The segment aged 80 and above is the most rapidly growing age group in developed countries and comprises the largest proportion of older persons in institutions (Sundstrom et al. 1994). Yet, most research into quality of life has focused on the general population, not on elderly people in institutions (Oleson et al. 1994, Campen van \& Kerkstra 1998). This paper sheds light on the quality of life of residents in Dutch nursing homes and the way this relates to the quality of the co-ordination of care.

Health care in nursing homes differs from country to country. The boundaries between the health care services of nursing homes, homes for the elderly, geriatric centres and rehabilitation centres vary as a result of national histories and policies (Newman 1988, Bartlett 1993, Ribbe 1993). A Dutch nursing home can be described as `an institution which provides temporary or permanent multidisciplinary treatment, guidance and support, and nursing care mainly for elderly patients with long-term, complex health problems, expressed primarily in terms of functional disorders and handicaps' (Ribbe 1993, p. 215). Although the care in nursing homes is multidisciplinary, nurses have an important contribution in the care for nursing home residents, because they spend a lot of time with the residents.

In this study, the relation between the quality of the co-ordination of nursing care and the quality of life of nursing home residents was investigated. A well founded co-ordination of care will lead to nursing care that meets the residents' physical and psycho-social needs and consequently improves the health conditions and the quality of life as perceived by the residents. Definitions of co-ordination of care often refer to the provision of tailormade care for clients and serves to improve the quality of care (Achterberg van et al. 1996). According to Lingen et al. (1990) co-ordination of care can be considered as one of the three dimensions of quality of nursing care in nursing homes. The other two dimensions are instrumental care and the quality of the social climate and living environment. In this concept, co-ordination of care is one of the aspects of quality of care. Co-ordination of nursing care involves activities like taking case histories, drawing up the nursing care plan, end of shift report, allocation of patients, consultation, and documentation (Lingen et al. 1990). Co-ordination of care aims at the provision of tailormade care, that is to diminish the gap between the residents' needs and nursing care supply. Nursing care that meets the residents' physical and psycho-social needs will promote the health conditions and the quality of life as perceived by the residents. On the other hand, discrepancies between residents' needs and received nursing care may affect the residents' perceived quality of life and his health conditions negatively. Quality of life is defined as the resident's judgement on his/her sensory, physical and psycho-social functioning and his/her perceived autonomy and perceived safety (Campen van \& Kerkstra 1998).

It should be noted that this definition, firstly, is restricted to the perspective of residents (Bowling 1991, 1995) and secondly, relates quality of life not only to health status (for instance sensory, physical functioning) but also to care and residence (perceived autonomy and safety). The relationship between co-ordination of care, the level of discrepancy between patients' needs and received nursing care, and the health status and perceived quality of life is summarized in Figure 1.

\section{[ FIGURE 1 ]}

\section{THE STUDY}

\section{Research questions}

Consistent with its aim and research model, this study addressed the following questions:

- What is the quality of co-ordination of nursing care in nursing homes?

- Is there a gap between the residents' needs and the received nursing care?

- What is the level of the perceived quality of life of nursing home residents and of their health conditions? 
Holtkamp, C.C.M., Kerkstra, A., Ribbe, M.W., Campen, C. van, Ooms, M.E.

The relation between quality of co-ordination of nursing care and quality of life in

Dutch nursing homes.

Journal of Advanced Nursing: 32, 2000, nr. 6, p. 1364-1373

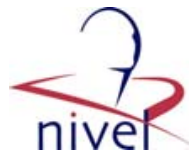

- How are the quality of co-ordination of care, the discrepancies between needs and received care, and the quality of life and health conditions of the residents related?

It is expected that high quality of co-ordination of care will diminish the gap between patients' needs and care supply, and consequently improve the health conditions and the perceived quality of life of the residents.

\section{METHODS}

\section{Sample}

A sample of 337 residents from 10 different Dutch nursing homes were included in the study. The inclusion criteria were that the residents were:

- admitted for long-term care on a somatic ward with an expected remaining duration of stay of longer than 9 months;

- able to understand simple questions and to answer 'yes' or 'no' verbally, or by pointing at the intended answer; or a family member is able and permitted to answer the questions;

- able to give informed consent according to the judgement of the investigator.

Psychogeriatric, terminal and rehabilitation patients were excluded by these criteria.

The group consisted of 119 males and 218 females with an average age of 78.6 years. Patients were diagnosed for cerebral haemorrhage (24.1\%), neurological disorders (19.6\%), cardiovascular diseases (11.3\%), musculoskeletal disorders (6.2\%), accidents (5.6\%), status after hip surgery or amputation (6.2\%), other diagnoses (17.2\%) and unknown (9.8\%).

\section{Measuring instruments}

\section{Co-ordination of nursing care}

The quality of co-ordination of nursing care was measured with the instrument for quality of nursing care in nursing homes developed and extensively validated by Lingen et al. (1990). Only the dimension 'Co-ordination of Care' was relevant and used in this study. The measuring instrument consists of quality standards and accompanying criteria, i.e. discrete items of practice which are observable and measurable. The quality standards concern six main aspects of the co-ordination of care:

- Taking a case history (4 standards, 6 criteria).

- Care plan (7 standards, 15 criteria).

- End of shift report (4 standards, 4 criteria).

- (Multidisciplinary) consultation (6 standards, 12 criteria).

- Patient allocation (2 standards, 2 criteria).

- Patient report (5 standards, 7 criteria).

A question is formulated for every single criterion in the instrument. Information about the level at which the criteria were met, was collected by analysis of the nursing records, by interviewing the residents and from a questionnaire filled in by the primary nurses. Depending on the criterion type, one of three sources of data was used. The questions were scored from 0 to 2 points, in which 0 means that the criterion was not met, 1 point when the criterion was met partially and 2 points when the criterion was met completely. Next, an index was computed for this dimension, the score of each resident was divided by the maximum score and multiplied by 100 . That gives ranges from $0 \%$ (lowest quality of co-ordination) to $100 \%$ (highest quality of co-ordination). In addition, separate indices were computed for the six main aspects mentioned above.

\section{Discrepancies between needs and care}

A questionnaire was developed to measure the unmet needs of the residents, that is the existence of a negative gap between the resident's care needs and the received care. The questionnaire was administered during a faceto- face interview with the residents. The residents were first asked whether or not they need help with a certain activity or problem, and next whether or not they received this care.

The needs were divided into three categories: 
Holtkamp, C.C.M., Kerkstra, A., Ribbe, M.W., Campen, C. van, Ooms, M.E.

The relation between quality of co-ordination of nursing care and quality of life in

Dutch nursing homes.

Journal of Advanced Nursing: 32, 2000, nr. 6, p. 1364-1373

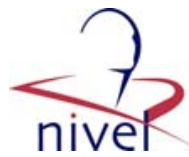

- Physical needs, that is the need for help with activities of daily living (ADL), such as bathing, dressing and walking (10 items).

- Needs in using aids and facilities, such as hearing and visual aids, use of telephone or a taxi (13 items).

- Psycho-social needs, such as help needed with feelings of sadness and depression, family problems and acceptance of physical deterioration (11 items).

When the resident expressed the need for help with a certain problem and did not receive this care, it concerned a negative gap. An index (number of negative gaps divided by total number of items, multiplied by 100) was computed for each category and for the total questionnaire, ranging from a minimum of $0 \%$ (no gap) to a maximum of $100 \%$ (maximum gap between needs and care supply).

\section{Quality of life}

To measure the perceived quality of life of the residents, the Quality of Life of Somatic Nursing Home Residents Questionnaire was used. This instrument, developed and validated in previous research by van Campen and Kerkstra (1998) has five dimensions:

- Sensory functioning ( 8 items, KR-20 $=0.79$ ). As indicator of this dimension the subscale pain of the Nottingham Health Profile (McEwen 1993) was used.

- Physical functioning (17 items, KR-20 = 0.78). This dimension was measured by the scale somatic autonomy of the Sickness Impact Profile (SIP68) (de Bruin et al. 1992, 1994).

- Psycho-social functioning (17 items, KR-20 $=0.79$ ). Life satisfaction of elderly people in institutions was used as indicator for this dimension and measured by the Philadelphia Geriatric Center Morale Scale (PGCMS) (Lawton 1975).

- Perceived autonomy (6 items, KR-20 $=0.76$ ). This subscale was developed by van Campen and Kerkstra (1998) and measures the extent to which the resident is free to decide to perform certain activities like the time to get up, to go to the toilet and to have visitors.

- Perceived safety $(6$ items, KR-20 $=0.54)$. This subscale was also developed by van Campen and Kerkstra (1998) and measures the extent to which the residents feel safe in the nursing home.

This instrument was used during a face-to-face interview with each resident. The answers on each item were scored on a two-point scale (yes/no). Next, an index (number of negative answers to items divided by total number of items, multiplied by hundred) was computed for each dimension and for the total questionnaire, ranging from a minimum of 0 (low quality of life) to a maximum of 100 (high quality of life). Consequently, a high score on for instance somatic autonomy means high physical autonomy, but a high score on pain means less pain.

\section{Health status}

To assess health conditions related to the quality of nursing care the prevalence of a number of health conditions were measured. These conditions are common health problems in nursing homes and are possibly related to nursing care (by prevention or treatment).

\section{Nutritional status}

This was assessed by means of the Arm muscle Area Index, a specified ratio of mid arm area and skin fold of mid arm (Potter et al. 1995). An existing formula calculates a score for men and women differently. The higher the score the better the nutritional status.

\section{The presence, severity and location of decubitus ulcers}

These were assessed using the 4-stage classification of the Resident Assessment Instrument (RAI), section M1. In this index the severity of decubitus can be scored from 1 to 4 . The number of decubitus ulcers can be counted and submitted to the 4 stages. The higher the score the higher the number and severity of decubitus ulcers (Morris et al. 1995).

\section{Presence/degree of incontinence}


Holtkamp, C.C.M., Kerkstra, A., Ribbe, M.W., Campen, C. van, Ooms, M.E.

The relation between quality of co-ordination of nursing care and quality of life in

Dutch nursing homes.

Journal of Advanced Nursing: 32, 2000, nr. 6, p. 1364-1373

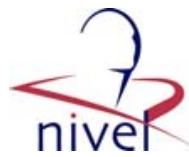

These were measured with the RAI 4 point scale (section H1) which range from 0 (completely continent) to 4 (completely incontinent). A distinction can be made between urine and faeces incontinence and were scored separately (Morris et al. 1995). For this study a distinction was made between the continent and the incontinent (regardless of the degree of incontinence).

\section{Incidence of falls}

These were recorded with the RAI according to section J4 of the Minimum Data Set (MDS) (Morris et al. 1995). This scale measures the number of falls, hipfractures and other fractures in the last 30 and 180 days separately. For this study a distinction was made between no falls or fractures during last 180 days and occasion of fall(s) or fracture(s) during last 180 days.

\section{Fluid status}

To measure the fluid status two items $(\mathrm{a}+\mathrm{c}$ ) were used of the section J1 of the RAI (Morris et al. 1995): (1) weight gain or loss of 3 or more pounds within a 7-day period (yes/no), and (2) dehydrated: output exceeds input (yes/no). A distinction was made between the presence (of one or two) and absence of the above mentioned criteria.

\section{Procedure}

The data were collected by means of the above-mentioned measuring instruments in the following way. First, the 337 residents were asked for a face-to-face interview. During this interview the resident part of the Co-ordination of Care scale, the Care Discrepancies questionnaire and the Quality of Life of Somatic Nursing Home Residents questionnaire were administered. Interviews were held with 279 (83\%) residents and with family members of 32 (9.5\%) residents, because those residents were not able to be interviewed. The other 26 (7.7\%) residents had given informed consent, but refused later on or were too ill to answer questions at the time of the interview. The duration of the interview was on the average 45 minutes. Second, every participating resident's primary nurse was asked to complete a questionnaire containing the nurse's part of the Co-ordination of Care scale and scored the MDS items regarding the health conditions of the resident, on the basis of her/his observations. For 310 residents (92\%), the nurses fulfilled this request and returned the questionnaire. Finally, research-assistants analysed the nursing records of the participating residents with the documentation part of the Coordination of Care scale and they also collected some background variables from the patient files. In total, the collection of data of one resident took about 2 hours. In the analyses, the resident was used as unit for observation.

\section{Analyses}

To investigate the relation between co-ordination of care, care discrepancies and quality of life, correlation coefficients were calculated between the variables. Scatterplots showed linear relations although they were not always clear. However, there were no deviant forms like U formed relations between the variables investigated.

To investigate the relation between co-ordination of care and health status and care discrepancies and health status, respectively, relative risks of health problems were calculated for the category residents with a high and low level of co-ordination of care (under and above the mean score) respectively, and care discrepancies (presence and absence of experienced care discrepancies).

\section{RESULTS}

\section{Quality of co-ordination of care}

In Table 1, the distributions of the scores are presented on the different quality aspects of coordination of care. The results show that the end of shift report and the patient allocation had the highest score. These aspects met on average $75 \%$ of the quality criteria formulated. This means, for instance, that during the end of the shift all nurses who care for a resident are present and that the end of shift report was in writing and explained orally, or that no more than two nurses were responsible for the different aspects of care of a resident during a shift. On the contrary, the quality of the care plan was much lower, on average only $46 \%$ of the quality criteria were met, i.e. most care plans did not 
Holtkamp, C.C.M., Kerkstra, A., Ribbe, M.W., Campen, C. van, Ooms, M.E.

The relation between quality of co-ordination of nursing care and quality of life in

Dutch nursing homes.

Journal of Advanced Nursing: 32, 2000, nr. 6, p. 1364-1373

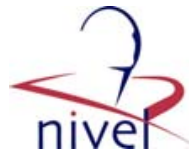

contain systematic information about the resident's needs, nursing goals, planning of care activities, contributions by the different members of the multidisciplinary team and about evaluations of care.

\section{[ TABLE 1 ]}

\section{Gaps between resident's needs and received care}

Regarding the care discrepancies, almost no gaps were found between physical needs and received care (Table 1). This means that most residents who need help with activities of daily living received the needed care. Regarding needs for help in using, adapting or obtaining aids and facilities about $10 \%$ of the needs of the residents were not met by the staff of the nursing homes. In particular, the unmet needs as regards help with problems of sight and hearing and to a lesser extent help with adapting visual aids and wheelchairs. However, the results regarding the psycho-social needs of the residents revealed a different picture. More than $40 \%$ of the needs were not fulfilled.

In more detail, most discrepancies between psychosocial needs and received care were experienced in needs relating to attention to personal values, living space, contact with other residents, recreational activities and striking up a conversation with the nurse. These needs were not met for more than $50 \%$ of the residents who need help in these areas. In addition, about $40 \%$ of the residents who needed help with family problems or with feelings of sadness or depression did not receive care for these problems.

\section{Quality of life and health status}

On quality of life, the dimension `felt safety' had the lowest mean score (42\%), followed by `somatic autonomy' (55\%). Although the moderate level of somatic autonomy, the level of autonomy experienced was best evaluated (77\%). This means that the extent to which the residents felt safe in the nursing home left a lot to be desired, whereas most residents felt free to decide on certain activities like the time to get up, to go out or to have visitors (Table 1).

The distribution of the presence of specific health problems is presented in Table 2 . The most frequent observed health problem was incontinence (74\%), followed by the nutritional problems of female residents (54\%). Lowest frequency of health problems was seen in the fluid status (4.3\%).

\section{[ TABLE 2 ]}

\section{Relations between co-ordination of care, unmet needs, quality of life and health conditions of the residents}

According to the research model, the quality of co-ordination of nursing care should be negatively related to the number of gaps between residents' needs and received care.

As expected, the results in Table 3 show predominantly negative correlations between the different aspects of the quality of co-ordination of care and the discrepancies between residents' needs and received care. The quality of case history taking correlated with negative significance with all the subscales as well as the total care discrepancy scale. This means that the higher the quality of case history taking the fewer gaps were shown between the residents' needs and the care received. The quality of the care plans also showed a significant negative relation with gaps in the help for the use of ADL-aids and facilities, and psycho-social needs. Furthermore, the results showed that the quality of patient allocation was related to fewer gaps between needs for help with aids and facilities and received care, and generally with fewer discrepancies between needs and received care. However, the positive relation between the quality of the end of shift report and the gaps between psycho-social needs and received care is in contradiction with the expectations derived from the research model. Finally, the summarized scores on the quality of co-ordination of care showed significant negative correlation with the total level of unmet needs.

\section{[ TABLE 3 ]}


Holtkamp, C.C.M., Kerkstra, A., Ribbe, M.W., Campen, C. van, Ooms, M.E.

The relation between quality of co-ordination of nursing care and quality of life in

Dutch nursing homes.

Journal of Advanced Nursing: 32, 2000, nr. 6, p. 1364-1373

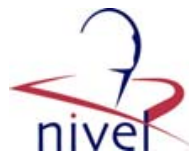

The next step in the research model was the relation between care discrepancies and quality of life and health status.

Table 4 shows that the total level of gaps between residents' needs and received care correlated significantly with four dimensions of perceived quality of life. That is the more discrepancies between needs and received care, the lower the residents' life satisfaction, felt safety and experienced autonomy. However, the relationship with somatic autonomy was not in the expected direction: the more gaps between needs and care, the higher the level of somatic autonomy. Looking at the correlations between the discrepancies of the separate needs and somatic autonomy, then only gaps concerning psycho-social needs correlated significantly positive with somatic autonomy. Furthermore, no relation was found between the level of care discrepancies and the dimension pain. Felt safety seemed to be the most important factor influenced by the gaps between residents' needs and received care.

\section{[ TABLE 4 ]}

To investigate the relations between care discrepancies and health status, first, correlations were calculated. However, no significant relations were found. To increase the contrast between residents with and without certain health problems, the residents were split into two groups for each health problem separately, and relative risks were calculated to investigate the relation in these more global groups. Concerning nutritional status, the residents were split up in groups above and below the found mean for Arm muscle Area Index. For the presence of decubitus ulcers, the residents were divided between no presence, and the presence for one or more symptoms of decubitus, regardless of the severity. Incontinence was split between completely continent and incontinent, for urine and faeces together. Falls were divided between no falls, and one or more falls and/or fractures during the last 180 days. Finally, symptoms of dehydration were split between no symptoms, and one or two symptoms of dehydration.

Table 5 presents relative risks of health problems for the residents exposed to the presence of experienced care discrepancies towards the residents who experienced no gaps between needs and received care. A relative risk $>1$ means a higher risk for the exposed residents. A relative risk $0<\mathrm{RR}$ $<1$ means a smaller risk for the exposed residents compared with the residents without experienced care discrepancies, which is the case for the risks of most health problems. However, the risks were not a significant divergent of 1 , which means that there is no difference in risk between the exposed and nonexposed group.

\section{[ TABLE 5 ]}

To investigate the direct relation between the quality of co-ordination of care and quality of life, correlations were calculated between each quality aspect and the separate dimensions of quality of life and are shown in Table 6.

\section{[ TABLE 6 ]}

The strongest relation between co-ordination of care and quality of life was found in the quality aspect 'patient allocation'. A higher quality of patient allocation was positively related to less pain, higher life satisfaction, more feelings of safety and to higher quality of life in general. Furthermore, a better quality case history taking was also related to greater feelings of safety, but unexpectedly to lower somatic autonomy.

In addition, another unexpected finding was that the quality of patient reports showed a negative relation with both the life satisfaction and the feelings of safety of the residents.

Finally, again no direct relations were found between the quality of the co-ordination of care and the risk of health problems in the residents. 
Holtkamp, C.C.M., Kerkstra, A., Ribbe, M.W., Campen, C. van, Ooms, M.E.

The relation between quality of co-ordination of nursing care and quality of life in

Dutch nursing homes.

Journal of Advanced Nursing: 32, 2000, nr. 6, p. 1364-1373

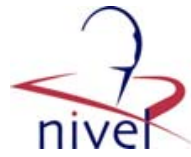

\section{DISCUSSION}

In the present study we examined the quality of co-ordination of nursing care, gaps between residents' needs and care supply, and the perceived quality of life in Dutch nursing homes. In addition, based on a research model the relations between these concepts were investigated.

The results on co-ordination of care showed that the quality was different for the various aspects, but in total $53 \%$ of the quality criteria were met. In another study, a total score of $42 \%$ on the quality of co-ordination of care was found for somatic wards of Dutch nursing homes (van der Made et al. 1994). Based on these results it can be concluded that there are quality aspects within co-ordination of care which could be further improved. Taking case history, making up care plans and patient report were evaluated with scores around $50 \%$. This means that a little more than half of the standards were completely or partially met. These aspects of co-ordination of care relating to assessment and documentation of patients' needs should receive more attention in the development of the nursing profession in Dutch nursing homes.

Gaps between needs and care supply were experienced most by the residents in psycho-social needs and less in physical needs. In addition, as regards the discrepancies between needs and care in using or obtaining aids and facilities, a relatively large number of discrepancies were experienced in the need for help with problems of sight and hearing. Apparently nurses have better insight into the physical needs and pay less attention to the assessment and documentation of psycho-social needs during case history taking or drawing up the care plans. This is in accordance with Ron and Bar-Tal (1993), Davis et al. (1997) and Griffiths (1998) who also found that nurses put more emphasis on meeting patients' physical needs and tend to overlook the psycho-social needs. In another study on the patients' perceived caring needs, it was found that the most conspicuous caring needs were confidence in the competence of nurses, comfort, guidance, dialogue and closeness which the patients expressed as problems, needs and desires (Fagerström et al. 1998).

The quality of life of the nursing home residents, measured on five dimensions, had the highest mean scores on psycho-social functioning (life satisfaction) and perceived autonomy. Therefore, although the somatic autonomy was rather low, the residents still experienced autonomy. The dimension `felt safety' had the lowest score. As regards pain, many residents were not completely free of pain. In a previous study into the quality of life of nursing home residents of somatic wards, the feelings of safety were better evaluated and those residents also felt less pain (Campen van \& Kerkstra 1998). The mean quality of life index measured in the present study was a little lower than in the study of van Campen and Kerkstra.

Regarding the health status, five measures were chosen which could possibly be related to the quality of co-ordination of care. The most frequent health problem was incontinence, almost $75 \%$ of the residents were more or less incontinent. Less often observed were falls and decubitus ulcers.

As regards the relationship among the above-mentioned concepts, based on the research model it was expected that high quality of co-ordination of care would diminish the gap between patients' needs and care supply, and consequently improve the health conditions and the perceived quality of the residents. The correlations found between co-ordination of care and care discrepancies were mostly in the expected direction: the higher the level of co-ordination of care, the less gaps between residents' needs and the care they received.

Evidence was also found for the relation between the level of unmet needs and the perceived quality of life: the less unmet needs, the higher the level of perceived quality of life of the residents. However, one unexpected relation was found; the level of somatic autonomy correlated positively with the total number of unmet needs. A possible explanation could be the focus of nurses on the stimulation of selfcare by residents who still have the capacities to perform out ADL activities themselves. Another possibility is that nurses pay attention to most severe patients first and overlook the patients who need less nursing care.

Contrary to the expectation no relations were found between the level of unmet needs and the health status of the residents. Even when the contrast made in the analyses was high between the groups, there were no differences found in the health problems between residents with and without gaps between needs and received care. In general, the results showed that nurses met residents' physical needs. This could be the reason why no relation was found between the level of unmet needs and health status. 
Holtkamp, C.C.M., Kerkstra, A., Ribbe, M.W., Campen, C. van, Ooms, M.E.

The relation between quality of co-ordination of nursing care and quality of life in

Dutch nursing homes.

Journal of Advanced Nursing: 32, 2000, nr. 6, p. 1364-1373

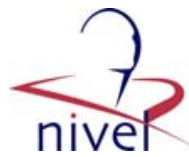

The findings regarding the direct relation between co-ordination of care and quality of life are more difficult to interpret because of the diversity of negative and positive correlations. The most clear relation was found between patient allocation and dimensions of quality of life. The quality of patient allocation (primary nursing) appeared to influence the quality of life in a positive direction. In a study of Nissen et al. (1997) an increased patient satisfaction, although not significant, was found after the implementation of primary nursing, which includes patient allocation. A survey in home care to the effects of primary nursing demonstrated that primary nursing positively affected patients' satisfaction with nursing care (Twardon \& Gartner 1991).

Unexpectedly, the quality patient report showed a negative relation with life satisfaction and feelings of safety. That means the higher the quality of the patient report, the less the life satisfaction and feelings of safety. A possible explanation may be that in the patient report the focus is on the (physical) health status of the residents. Overall, the correlations between the quality of co-ordination of care and the perceived quality of life of the nursing home residents were only around 0.20 , so no strong relations were found.

\section{Study limitations}

A limitation of this research is that correlational procedures were applied because of the crosssectional design of the study. These techniques provide us with associations, from which we identified variables which may determine the quality of life of nursing home residents, but not causal explanations. Therefore, we recommend that the research model be tested in a future study with a longitudinal design.

\section{CONCLUSION}

In conclusion, this study showed that co-ordination of care can affect the perceived quality of life of nursing home residents. The relation is stronger when the unmet needs of the residents are also taken into account. Tailormade care, that is care attuned to the residents' needs, apparently is an important instrument for residents' perceived quality of life.

To meet residents' needs it is important to assess these needs accurately before drawing up the nursing care plan. The psycho-social aspects in particular showed a gap in residents' needs and the care they received. Apparently the priority of care currently lies in meeting residents' physical needs.

It might be easier too to assess physical needs than psycho-social needs, because physical status is more visible and the assessment procedure more integrated in the nursing care. An integrated instrument in which the physical and psycho-social assessment procedures are both represented should be available for nurses to complete the assessment of residents' needs.

The Resident Assessment Instrument (RAI) is an computerized instrument to assess residents' physical, psychological and social needs (Morris et al. 1995). This instrument can be used by different disciplines involved in the care of the residents of nursing homes. Individual care plans are formulated on the basis of these structured assessments. A study conducted in Sweden found that the nursing staff developed increased understanding of the patients' abilities by using the RAI. Most of the staff also thought that the instrument improved the documentation in nursing records. (Hansebo et al. 1998). In the next study, the effect of the implementation of this instrument will be evaluated on the quality of nursing care and the quality of life of residents in Dutch nursing homes.

\section{ACKNOWLEDGEMENTS}

This research project was financed by the Dutch Council for Medical and Health Research (NWO), research program 'Chronic diseases'.

\section{TABLES AND FIGURES}


Holtkamp, C.C.M., Kerkstra, A., Ribbe, M.W., Campen, C. van, Ooms, M.E.

The relation between quality of co-ordination of nursing care and quality of life in

Dutch nursing homes.

Journal of Advanced Nursing: 32, 2000, nr. 6, p. 1364-1373

Table 1 Distributions of co-ordination of nursing care, gaps between residents' needs and received care, and quality of life of nursing home residents

\begin{tabular}{lccrrr}
\hline & $n$ & Mean & Min & Max & SD \\
\hline Co-ordination of care (0-100\%) & & & & \\
$\quad$ Case history taking & 337 & $54 \cdot 1$ & $0 \cdot 0$ & $100 \cdot 0$ & $18 \cdot 3$ \\
Care plan & 337 & $46 \cdot 4$ & $7 \cdot 1$ & $78 \cdot 6$ & $12 \cdot 5$ \\
End of shifts report & 310 & $75 \cdot 0$ & $25 \cdot 0$ & $100 \cdot 0$ & $19 \cdot 8$ \\
Consultation & 313 & $53 \cdot 3$ & $0 \cdot 0$ & $100 \cdot 0$ & $20 \cdot 8$ \\
Patient allocation & 320 & $74 \cdot 7$ & $0 \cdot 0$ & $100 \cdot 0$ & $35 \cdot 2$ \\
Patient report & 337 & $68 \cdot 9$ & $0 \cdot 0$ & $100 \cdot 0$ & $9 \cdot 9$ \\
Total & 337 & $53 \cdot 5$ & $11 \cdot 8$ & $81 \cdot 6$ & $10 \cdot 4$ \\
Care discrepancies (0-100\%) & & & & \\
Physical needs & 288 & $2 \cdot 2$ & $0 \cdot 0$ & $100 \cdot 0$ & $9 \cdot 9$ \\
Aids and facilities & 290 & $9 \cdot 6$ & $0 \cdot 0$ & $100 \cdot 0$ & $20 \cdot 9$ \\
Psycho-social needs & 226 & $42 \cdot 0$ & $0 \cdot 0$ & $100 \cdot 0$ & $41 \cdot 3$ \\
Total & 302 & $13 \cdot 0$ & $0 \cdot 0$ & $100 \cdot 0$ & $17 \cdot 8$ \\
Quality of life (0-100 points) & & & & \\
Pain & 311 & $65 \cdot 0$ & $0 \cdot 0$ & $100 \cdot 0$ & $29 \cdot 7$ \\
Somatic autonomy & 311 & $55 \cdot 1$ & $0 \cdot 0$ & $98 \cdot 6$ & $22 \cdot 4$ \\
Life satisfaction & 311 & $71 \cdot 2$ & $0 \cdot 0$ & $100 \cdot 0$ & $29 \cdot 0$ \\
Felt safety & 311 & $42 \cdot 0$ & $0 \cdot 0$ & $98 \cdot 6$ & $21 \cdot 0$ \\
Perceived autonomy & 311 & $77 \cdot 3$ & $0 \cdot 0$ & $100 \cdot 0$ & $32 \cdot 0$ \\
Total & 311 & $55 \cdot 8$ & $6 \cdot 0$ & $94 \cdot 0$ & $15 \cdot 0$ \\
\hline
\end{tabular}

Table 2 Distributions of indicators of health status

\begin{tabular}{|c|c|c|c|c|c|c|}
\hline \multirow[b]{2}{*}{ Health status } & \multicolumn{2}{|c|}{$\begin{array}{l}\text { Presence of } \\
\text { health problem }\end{array}$} & \multicolumn{2}{|c|}{$\begin{array}{l}\text { Absence of } \\
\text { health problem }\end{array}$} & \multicolumn{2}{|c|}{ Total } \\
\hline & $n$ & $\%$ & $n$ & $\%$ & $n$ & $\%$ \\
\hline \multicolumn{7}{|c|}{ Nutritional status } \\
\hline Males & 45 & $50 \cdot 6$ & 44 & $49 \cdot 4$ & 89 & 100 \\
\hline Females & 79 & $54 \cdot 1$ & 67 & $45 \cdot 9$ & 146 & 100 \\
\hline Decubitus & 73 & $28 \cdot 2$ & 186 & $71 \cdot 8$ & 259 & 100 \\
\hline Incontinence & 230 & $74 \cdot 2$ & 80 & $25 \cdot 8$ & 310 & 100 \\
\hline Falls & 44 & $14 \cdot 2$ & 266 & $85 \cdot 8$ & 310 & 100 \\
\hline Fluid status & 13 & $4 \cdot 3$ & 289 & $95 \cdot 7$ & 302 & 100 \\
\hline
\end{tabular}

Table 3 Pearson productmoment correlations between co-ordination of care and gaps between residents' needs and received care $(n=311)$

\begin{tabular}{lllll}
\hline & $\begin{array}{l}\text { Physical } \\
\text { needs }\end{array}$ & $\begin{array}{l}\text { Needs with aids } \\
\text { and facilities }\end{array}$ & $\begin{array}{l}\text { Psycho-social } \\
\text { needs }\end{array}$ & $\begin{array}{l}\text { Care discrepancies } \\
\text { total }\end{array}$ \\
\hline Case history taking & $-0 \cdot 13^{*}$ & $-0 \cdot 21^{* *}$ & $-0 \cdot 18^{* *}$ & $-0 \cdot 23^{* *}$ \\
Care plan & $-0 \cdot 11$ & $-0 \cdot 15^{*}$ & $-0 \cdot 19^{* *}$ & $-0 \cdot 16^{* *}$ \\
End of shift report & $0 \cdot 04$ & $0 \cdot 01$ & $0 \cdot 19^{* *}$ & $-0 \cdot 01$ \\
Consultation & $-0 \cdot 12$ & $-0 \cdot 03$ & $-0 \cdot 07$ & $-0 \cdot 08$ \\
Patient allocation & $-0 \cdot 01$ & $-0 \cdot 17^{* *}$ & $-0 \cdot 02$ & $-0 \cdot 12^{*}$ \\
Patient report & $-0 \cdot 04$ & $0 \cdot 02$ & $-0 \cdot 13$ & $0 \cdot 09$ \\
Co-ordination of care total & $-0 \cdot 10$ & $-0 \cdot 20^{* *}$ & $-0 \cdot 12$ & $-0 \cdot 19^{* *}$ \\
\hline
\end{tabular}

${ }^{*} P \leq 0.05$ (2 tailed); ** $P \leq 0.01$ (2-tailed). 
Holtkamp, C.C.M., Kerkstra, A., Ribbe, M.W., Campen, C. van, Ooms, M.E. The relation between quality of co-ordination of nursing care and quality of life in Dutch nursing homes.

Journal of Advanced Nursing: 32, 2000, nr. 6, p. 1364-1373

\begin{tabular}{lllll}
\hline & $\begin{array}{l}\text { Physical } \\
\text { needs }\end{array}$ & $\begin{array}{l}\text { Needs with aids } \\
\text { and facilities }\end{array}$ & $\begin{array}{l}\text { Psycho-social } \\
\text { needs }\end{array}$ & $\begin{array}{l}\text { Care discrepancies } \\
\text { total }\end{array}$ \\
\hline Pain & $-0 \cdot 01$ & $-0 \cdot 07$ & $-0 \cdot 01$ & $-0 \cdot 02$ \\
Somatic autonomy & $0 \cdot 11$ & $0 \cdot 08$ & $0 \cdot 14^{*}$ & $0 \cdot 23^{* *}$ \\
Life satisfaction & $-0 \cdot 16^{* *}$ & $-0 \cdot 12$ & $-0 \cdot 11$ & $-0 \cdot 21^{* *}$ \\
Felt safety & $-0 \cdot 36^{* *}$ & $-0 \cdot 13^{*}$ & $-0 \cdot 33^{* *}$ & $-0 \cdot 37^{* *}$ \\
Experienced autonomy & $-0 \cdot 15^{*}$ & $-0 \cdot 18^{* *}$ & $-0 \cdot 12$ & $-0 \cdot 22^{* *}$ \\
Quality of life total & $-0 \cdot 13^{*}$ & $-0 \cdot 05$ & $-0 \cdot 07$ & $-0 \cdot 10$ \\
\hline
\end{tabular}

Table 4 Pearson productmoment correlations between level of care discrepancies and quality of life of nursing home residents $(n=311)$

${ }^{*} P \leq 0 \cdot 05$ (2 tailed); ${ }^{*} P \leq 0 \cdot 01$ (2-tailed).

Table 5 Relative risks of health problems of residents exposed to experienced gaps between needs and care supply towards residents with absence of experienced care discrepancies

\begin{tabular}{|c|c|c|}
\hline Residents with health problems in: & $\mathrm{RR}$ & Confidence \\
\hline \multicolumn{3}{|l|}{ Interval nutritional status } \\
\hline Men & $0 \cdot 91$ & $(0 \cdot 56-1 \cdot 48)$ \\
\hline Women & $0 \cdot 86$ & $(0 \cdot 64-1 \cdot 17)$ \\
\hline Decubitus & 0.96 & $(0 \cdot 63-1 \cdot 46)$ \\
\hline Incontinence & $1 \cdot 09$ & $(0 \cdot 94-1 \cdot 26)$ \\
\hline Falls & $1 \cdot 24$ & $(0 \cdot 69-2 \cdot 22)$ \\
\hline Fluid status & $0 \cdot 51$ & $(0 \cdot 24-1 \cdot 07)$ \\
\hline
\end{tabular}

\begin{tabular}{lccccrr}
\hline & Pain & $\begin{array}{l}\text { Somatic } \\
\text { autonomy }\end{array}$ & $\begin{array}{l}\text { Life } \\
\text { satisfaction }\end{array}$ & $\begin{array}{l}\text { Felt } \\
\text { safety }\end{array}$ & $\begin{array}{l}\text { Perceived } \\
\text { autonomy }\end{array}$ & QOL \\
\hline Total case history taking & $-0 \cdot 01$ & $-0 \cdot 14^{*}$ & $-0 \cdot 09$ & $0 \cdot 16^{* *}$ & $0 \cdot 04$ & $-0 \cdot 08$ \\
Care plan & $-0 \cdot 05$ & $0 \cdot 02$ & $0 \cdot 07$ & $0 \cdot 13^{*}$ & $0 \cdot 04$ & $0 \cdot 06$ \\
End of shift report & $-0 \cdot 13^{*}$ & $-0 \cdot 07$ & $-0 \cdot 02$ & $-0 \cdot 09$ & $0 \cdot 01$ & $-0 \cdot 10$ \\
Consultation & $0 \cdot 12$ & $0 \cdot 11$ & $-0 \cdot 10$ & $-0 \cdot 00$ & $0 \cdot 05$ & $0 \cdot 01$ \\
Patient allocation & $0 \cdot 13^{*}$ & $0 \cdot 04$ & $0 \cdot 19^{* *}$ & $0 \cdot 13^{*}$ & $0 \cdot 04$ & $0 \cdot 18^{* *}$ \\
Patient report & $0 \cdot 10$ & $0 \cdot 06$ & $-0 \cdot 15^{* *}$ & $-0 \cdot 11^{*}$ & -0.08 & $-0 \cdot 05$ \\
Co-ordination of care total & $0 \cdot 00$ & $-0 \cdot 01$ & -0.03 & $0 \cdot 11$ & $0 \cdot 05$ & $0 \cdot 01$ \\
\hline
\end{tabular}

Table 6 Pearson productmoment correlations between co-ordination of care and quality of life of nursing home residents $(n=311)$

${ }^{*} P \leq 0 \cdot 05$ (2-tailed); **P $\leq 0 \cdot 01$ (2-tailed)

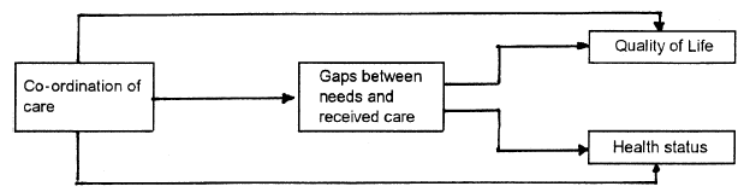

Figure 1 Research model.

\section{REFERENCES}

1. Achterberg van T., Stevens F.C.J., Crebolder H.F.J.M., Witte de L.P. \& Philipsen H. (1996) Co-ordination of care: effect on the continuity and quality of care. International Journal of Nursing Studies 33, 638-650.

2. Bartlett H. (1993) Nursing Homes for Elderly People: Questions of Quality and Policy. Harwood Ac. Publishers, Chur, Switzerland.

3. Bowling A. (1991) Measuring Health: A Review of Quality of Life Measurement Scales. Open University Press, Milton Keynes, Philadelphia.

4. Bowling A. (1995) Measuring Disease: A Review of Disease Specific Quality of Life Measurement Scales. Open University Press, Philadelphia.

5. Bruin de A.F., Diedericks J.P.M., Witte de L.P., Stevens F.C.J. \& Philipsen H. (1994) The development of a short generic, version of the sickness impact profile. Journal of Clinical Epidemiology 47, 407-418. 
Holtkamp, C.C.M., Kerkstra, A., Ribbe, M.W., Campen, C. van, Ooms, M.E.

The relation between quality of co-ordination of nursing care and quality of life in

Dutch nursing homes.

Journal of Advanced Nursing: 32, 2000, nr. 6, p. 1364-1373

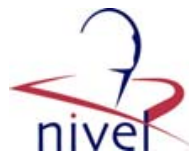

6. Bruin de A.F., Witte de L.P., Stevens F. \& Diedericks J.P.M. (1992) Sickness impact profile: the state of the art of a generic functional status measure. Social Science and Medicine $\mathbf{3 5}$, 1003-1014.

7. Campen van C. \& Kerkstra A. (1998) Ervaren kwaliteit van leven van oudere somatische verpleeghuispatiënten. constructie van een meetsintrument. Tijdschrift Voor Gerontologie En Geriatrie 29, 11-18.

8. Davies S., Laker S. \& Ellis L. (1997) Promoting autonomy and independence for older people within nursing practice: a literature review. Journal of Advanced Nursing 26, 408-417.

9. Fagerström L., Erikson K. \& Bergbom Engberg I. (1998) The patient's perceived caring needs as a message of suffering. Journal of Advanced Nursing 28, 978-987.

10. Grant N.K., Reimer M. \& Bannatyne J. (1996) Indicators of quality in long term care facilities. International Journal of Nursing Studies 33, 469-478.

11. Griffiths P. (1998) An investigation into the description of patients' problems by nurses using two different needs-based nursing models. Journal of Advanced Nursing 28, 969-977.

12. Hansebo G., Kihlgren M., Ljunggren G. \& Winblad B. (1998) Staff views on the resident assessment instrument, RAI/MDS, in nursing homes, and the use of the cognitive performance scale, CPS, in different levels of care in Stockholm, Sweden. Journal of Advanced Nursing 28, 642-653.

13. Lawton M.P. (1975) The Philadelphia geriatric morale scale: a revision. Journal of Gerontology 30, 85-89.

14. Lingen B., Hollands L., Bergen van B., Lemmen T. \& Visser G. (1990) Kwaliteit van verpleegkundige zorg in verpleeghuizen: een meetinstrument. De Tijdstroom, Lochem, the Netherlands.

15. McEwen J. (1993) The Nottingham health profile. In Quality of Life Assessment: Key Issues in the 1990s (Walker S.R., Rosser R.M. eds), Kluwer, Dordrecht, pp. 111-130.

16. Morris J.N., Murphy K. \& Nonemaker S. (1995) Long term resident assessment instrument: user's manual version 2.0. Baltimore, Maryland, United States.

17. Newman S. (1998) Worlds Apart? Long-term Care in Australia and the United States. Haworth Press, New York.

18. Nissen J.M.J.F., Boumans N.P.G. \& Landeweerd J.A. (1997) Primary nursing and quality of care: a Dutch study. International Journal of Nursing Studies 34, 93-102.

19. Oleson M., Heading C.M.C., Glyn Shadick K. \& Bistodeau J.A. (1994) Quality of life in longstay institutions in England: nurse and resident perceptions. Journal of Advanced Nursing 20, 23-32.

20. Potter J., Klipstein K., Reily J.J. \& Roberts M. (1995) The nutritional status and clinical course of acute admissions to a geriatric unit. Age-Aging 24, 131-136.

21. Ribbe M.W. (1993) Care for the elderly: the role of the nursing home in the Dutch health care system. International Psychogeriatrics 5, 213-222.

22. Ron R. \& Bar-Tal Y. (1993) Quality nursing care survey, 1988-90. Quality Assurance in Healthcare 5, 57-65.

23. Sundstrom G., Tinker A., Wiener J. \& Davies B. (1994) Caring for Frail Elderly People: New Directions in Care. Organization for Economic Co-operation and Development, Paris.

24. Twardon C.A. \& Gartner M.B. (1991) Empowering nurses. Patient satisfaction with primary nursing in home health. Journal of Nursing Administration 21, 39-43.

25. Van der Made F., Jongerden I., Hollands L. \& Halfens R. (1994) Kwaliteit van de verpleging en verzorging van Parkinsonpatiënten in het verpleeghuis. Rijksuniversiteit Limburg, Maastricht, The Netherlands. 